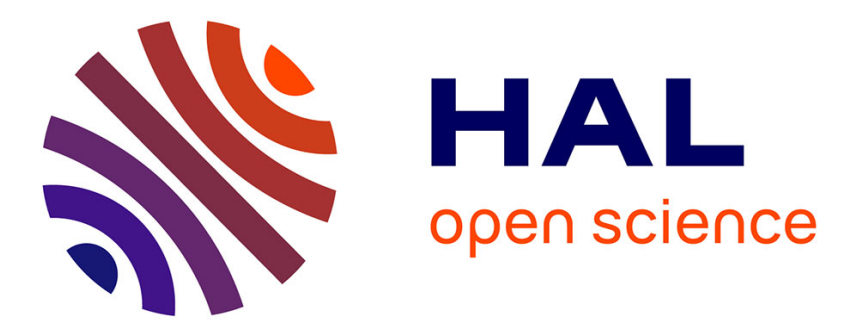

\title{
Determining the specific area of porous acoustic materials from water extraction data
}

\author{
Philippe Leclaire, Mark Swift, Kirill Horoshenkov
}

\section{To cite this version:}

Philippe Leclaire, Mark Swift, Kirill Horoshenkov. Determining the specific area of porous acoustic materials from water extraction data. Journal of Applied Physics, 1998, 10.1063/1.368985 . hal01330330

\section{HAL Id: hal-01330330 \\ https://hal.science/hal-01330330}

Submitted on 10 Jun 2016

HAL is a multi-disciplinary open access archive for the deposit and dissemination of scientific research documents, whether they are published or not. The documents may come from teaching and research institutions in France or abroad, or from public or private research centers.
L'archive ouverte pluridisciplinaire $\mathbf{H A L}$, est destinée au dépôt et à la diffusion de documents scientifiques de niveau recherche, publiés ou non, émanant des établissements d'enseignement et de recherche français ou étrangers, des laboratoires publics ou privés. 


\title{
Determining the specific area of porous acoustic materials from water extraction data
}

\author{
P. Leclaire, M. J. Swift, and K. V. Horoshenkov \\ Department of Civil and Environmental Engineering, University of Bradford, Bradford BD7 IDP, \\ West Yorkshire, United Kingdom
}

\begin{abstract}
The internal pore surface area per unit mass of solid (specific area) is an important parameter for the physical study of sound wave propagation in porous media. It is shown that this parameter can be evaluated with a reasonable accuracy from the integration of the water extraction curve (volume of water extracted versus applied pressure). This method is nonacoustic, modelless and well adapted to acoustic materials. It is a complementary method to the standard BET (Brunauer, Emmet, Teller) technique, generally used for powders in chemistry and the pharmaceutical industry. Experiments are made on loose glass beads of a few hundred microns diameter and results are compared to theoretical values. Results on heterogeneous materials used in civil engineering and in noise control are also given. The parameters necessary for the description of modern acoustic materials are estimated from the specific area measured by this method.
\end{abstract}

\section{INTRODUCTION}

The propagation of sound waves in porous media is a complex phenomenon involving elastic and kinetic energy exchanges between the solid and the fluid and visco-thermal interactions. This topic is studied in the area of geophysics, petroleum engineering and underwater acoustics and in the fields of noise control and civil engineering, where the saturating fluid is air. A current problem which is receiving attention is the description of the high frequency behavior without the need to make assumptions about the pore shape and using appropriate parameters, i.e., measurable parameters with a physical meaning. Johnson et al. ${ }^{1}$ and Champoux and Allard ${ }^{2-4}$ have expressed the high frequency behavior in terms of overall coefficients integrating the complexity of the pore shape; these are the viscous length $\Lambda$ and the thermal length $\Lambda^{\prime}$. Yamamoto and Turgut ${ }^{5}$ and Attenborough ${ }^{6}$ have shown that the size of the pore can affect the results and have included a distribution in pore size in the acoustic models. The parameters defined in all these models can be measured under certain conditions and for certain materials. In the case of polyurethane foams, simple experiments using ultrasound in air or in different gases have been proposed to measure the tortuosity ${ }^{7}$ and the viscous and thermal lengths ${ }^{8,9}$ but these methods are limited to high porosity materials producing a fairly low sound attenuation. In addition, scattering of ultrasonic waves ${ }^{10}$ due to the small wavelengths involved can be a limiting factor.

In this article, we show that the parameters involved in the acoustic description of porous media can be evaluated from the measurement of specific area. The specific area, defined as the internal pore surface area per unit mass of solid, is obtained from a nonacoustic method applicable to many materials without making any assumption on the pore shape. In particular, the experiments lead to a direct determination of $\Lambda^{\prime}$. This parameter is useful for the study, at the pore scale, of modern acoustic materials from the physical standpoint and is of a major importance for the description of thermal exchanges associated to the sound wave propagation in air-filled porous structures. ${ }^{4}$ This method using extraction of water has never been used in acoustics for measuring the specific area.

\section{CAPILLARITY AND SPECIFIC AREA}

\section{A. Surface tension and capillary law}

Water rising in a narrow tube by the capillary effect is a very well known phenomenon (see Lowell and Shields ${ }^{11}$ for example). It is described by the concepts of surface tension and contact angle, and a capillary law. The surface tension is used to describe the mechanical tension of the interface separating two fluids while the capillary law gives the condition of mechanical equilibrium in a capillary system. For an interface defined by its two principal radii of curvature $r_{1}$ and $r_{2}$, the capillary law is

$$
\Delta P=\sigma\left(\frac{1}{r_{1}}+\frac{1}{r_{2}}\right),
$$

where $\Delta P$ is the pressure difference between the two fluids and $\sigma$ the surface tension in $\mathrm{N} / \mathrm{m}$. The curvature of the interface depends on the pore geometry and the contact angle $\theta$.

For a narrow circular tube of radius $r$ the interface is a portion of the surface of a sphere and $r_{1}=r_{2}=r / \cos \theta$. The pressure difference $\Delta P$ is then given by

$$
\Delta P=\frac{2 \sigma \cos \theta}{r} \text {. }
$$

The capillary law for slit-like pores is obtained when either $r_{1}$ or $r_{2}$ tends to infinity in Eq. (1): 


$$
\Delta P=\frac{\sigma \cos \theta}{a},
$$

where $a$ is the semiwidth of the slits.

\section{B. Specific area from the water extractlon curve}

Rootare and Prenzlow ${ }^{12}$ have proposed a method for measuring the pore surface area of various powders from mercury intrusion data and compared their results to those provided by the standard BET method (Brunauer, Emmet and Teller ${ }^{13}$ ). The method of Rootare and Prenzlow is based on the calculation of the work $d W$ required to raise a liquid in a capillary. This work is equal the work required to force the liquid out ${ }^{11}$ and the method can be adapted and applied in the case of water extraction. The contact angle for wetting liquids being between $0^{\circ}$ and $90^{\circ}, \cos \theta$ is greater than zero and

$$
d W=\sigma_{\mathrm{wa}} \cos \theta d A,
$$

where $\sigma_{\mathrm{wa}}$ is the surface tension of the water/air interface and $d A$ is the surface area covered by the liquid along the pore wall during the process. This work is also equal to the product $P d V$ of the volume $d V$ of displaced liquid and the increase of pressure $P$ required to move the liquid. Thus the following relation is obtained:

$$
\sigma_{\mathrm{wa}} \cos \theta d A=P d V \text {. }
$$

Integrating Eq. (5) from zero to the total pore volume $V_{\text {Tot }}$ yields the total pore surface area:

$$
S=\frac{1}{\sigma_{\mathrm{wa}} \cos \theta} \int_{0}^{V_{t o t}} P d V
$$

Equations (4)-(6) show that no particular assumption on the pore shape is made for the calculation of the specific area.

\section{EXPERIMENTS}

Evans ${ }^{14}$ has accomplished extensive experimental work on the measurement of pore size distribution for the description of the acoustic properties of porous media. ${ }^{6}$ This article concerns the specific area and not the pore size distribution but the same experimental principle is used. An improved version of Evans' setup giving more accurate and reliable results has been developed. The experimental principle (Fig. 1) consists of applying a pressure drop to a sample initially saturated with water and measuring the volume of water extracted by capillary action. The pressure drop is obtained by lowering the burette from the zero position, taken at the top of the sample. This configuration insures a constancy of the head level and therefore, of the applied pressure variations. The excess water drained out of the sample flows from the top of the burette into a measuring cylinder.

Preliminary experimental work consists of washing each sample and evaluating the volume, the porosity and the dry density. During the experiment, all the necessary information is obtained from the measurement of the head level and of the cumulative volume of water extracted. The remaining water in the sample after an experiment was less than $15 \%$ for the worst case (Coustone samples).

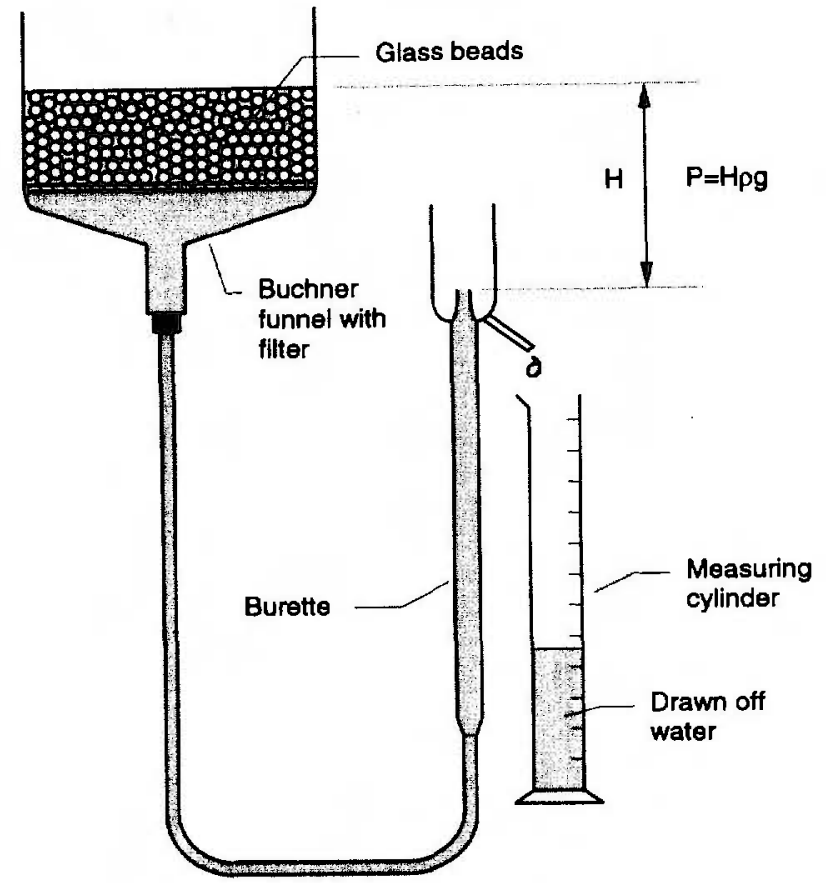

FIG. 1. Experimental principle for measuring the surface area of porous materials.

\section{RESULTS}

The results for three grades of loose glass beads and three acoustic samples (Coustone) made of flint particles consolidated with a binder are presented. Basic information on each sample is given in Table I. For the Coustone samples, $N$ corresponds to the nominal concentration of binder (3\% in mass) while $\frac{1}{2}$ and 2 correspond respectively to half and twice the nominal concentration. The extraction curve, i.e., the volume of water removed normalized by the total volume extracted from the sample, is plotted in Fig. 2 as a function of the applied pressure for the three grades of glass beads and for Coustone $N$ (similar results as for the grades $N$ have been obtained for the grades $\frac{1}{2}$ and 2). Applying Eq. (6), the total surface area is deduced for each sample from the area of the left half space defined by the curve $V(P)$ and the axes $(P, 0),(P, 1)$ and $(0, V)$. The constants chosen for the calculation of the integral are $\sigma_{\text {wa }}$ $=0.07275 \mathrm{~N} / \mathrm{m}$ and $\theta=0^{\circ}$. Since the pressures involved are small when using water, it is assumed that the constants do not to vary during the experiment. The applied pressure is

\begin{tabular}{|c|c|c|c|c|c|}
\hline Grade & $\begin{array}{l}\text { Particle size } \\
\quad(\mathrm{mm})\end{array}$ & Porosity & $\begin{array}{c}\text { Dry density } \\
\left(\mathrm{kg} / \mathrm{m}^{3}\right)\end{array}$ & $\begin{array}{l}\text { Volume } \\
(\mathrm{m} /)\end{array}$ & $\begin{array}{l}\text { Thickness } \\
\text { (cm) }\end{array}$ \\
\hline Beads 136-014 & $0.68 \pm 0.12$ & 0.385 & $(1-0.385) \times 2480$ & 300 & $\approx 2.3$ \\
\hline Beads 136-010 & $1.11 \pm 0.15$ & 0.365 & $(1-0.365) \times 2480$ & 200 & $\simeq 1.5$ \\
\hline Beads 136-021 & $1.64 \pm 0.15$ & 0.362 & $(1-0.362) \times 2480$ & 200 & $\approx 1.5$ \\
\hline Coustone $N$ & $\approx 1$ & 0.337 & 1427 & 182 & 1.2 \\
\hline Coustone $\frac{1}{2}$ & $\approx 1$ & 0.365 & 1385 & 182 & 1.2 \\
\hline Coustone 2 & $\approx 1$ & 0.315 & 1439 & 182 & 1.2 \\
\hline
\end{tabular}
obtained from the head level difference $H$ with respect to the zero position:

TABLE I. Samples characteristics. 


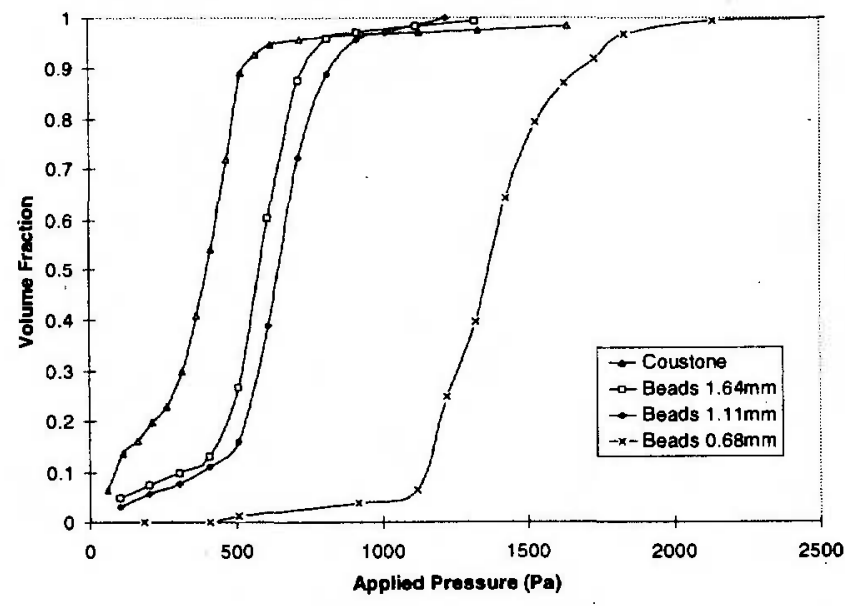

FIG. 2. Normalized volume of water extracted of the porous sample as a function of the applied pressure.

$$
P=\rho g H,
$$

where $\rho$ is the fluid density and $g$ the gravitational constant. The specific area $S_{S}$ is then obtained by dividing the total surface area $S$ by the mass of the sample.

Theoretical values can be calculated in the case of glass beads. For a collection of identical spherical particles of radius $r_{s}$, of density $\rho_{s}\left(\rho_{s}=2480 \mathrm{~kg} / \mathrm{m}^{3}\right.$ for glass $)$ and without surface roughness, the specific area is given by

$$
S_{S \mathrm{Th}}=\frac{3}{r_{s} \rho_{s}} .
$$

The results are summarized in Table II. The thermal length appearing in this table is explained and discussed in Sec. VI.

\section{DISCUSSION OF RESULTS}

The comparison of specific area measured by water extraction with theoretical values is possible only for glass beads. A reasonable agreement of $6.5 \%$ and $9.9 \%$ has been found between the measured values and the calculated ones for the two smallest grades (Table II). The larger discrepancy of $17.5 \%$ obtained for the largest beads is likely due to the gravitational force acting on the fluid. This effect adds to the capillary force and increases the actual force applied to the water. An order of magnitude of the ratio $q$ of the gravitational to capillary forces between the top and the bottom of the sample can be calculated by

TABLE 11. Results.

\begin{tabular}{lcccc}
\hline \hline Grade & $\begin{array}{c}\text { Specific area } \\
\left(\mathrm{m}^{2} / \mathrm{kg}\right)\end{array}$ & $\begin{array}{c}\text { Theoretical value } \\
\left(\mathrm{m}^{2} / \mathrm{kg}\right)\end{array}$ & $\begin{array}{c}\text { Difference } \\
(\%)\end{array}$ & $\begin{array}{c}\text { Thermal length } \\
(\mu \mathrm{m})\end{array}$ \\
\hline Beads $136-014$ & 3.79 & 3.56 & 6.5 & 133 \\
Beads $136-010$ & 1.96 & 2.18 & 9.9 & 236 \\
Beads $136-021$ & 1.74 & 1.48 & 17.5 & 263 \\
Coustone $N$ & 0.92 & $\cdots$ & $\cdots$ & 511 \\
Coustone $\frac{1}{2}$ & 1.2 & $\ldots$ & $\cdots$ & 431 \\
Coustone 2 & 1.3 & $\ldots$ & $\cdots$ & 340 \\
\hline \hline
\end{tabular}

$$
q=\frac{\Delta P_{g}}{\Delta P}=\frac{\rho g e r}{2 \sigma_{\text {wa }} \cos \theta},
$$

where $e$ is the thickness of the sample. For a sample of 1.5 $\mathrm{cm}$ thickness made of $1.64 \mathrm{~mm}$ diameter beads, the average pore size is about $400 \mu \mathrm{m}$ and $q$ is of the order of $20 \%$ while it is less for smaller beads. According to Eq. (9), the method can be optimized by reducing the thickness of the sample or by increasing the surface tension while keeping the contact angle close to $0^{\circ}$. For the grades $136-010$ and 136-021, the experiments were initially performed in samples of $3 \mathrm{~cm}$ thickness. The results obtained for the specific area were respectively 2.42 and $1.94 \mathrm{~m}^{2} / \mathrm{kg}$ and the deviation from the theoretical values respectively $11.0 \%$ and $31 \%$. This confirms the influence of gravity and shows that the precision can be improved for coarse materials by reducing the sample thickness.

The limitations of the method are the dependence of the contact angle on the material, the effect of gravity and the effect of the remaining water trapped in the cracks at the end of the experiment. In addition, no chemical reaction must occur between water and solid. This method is limited to materials with small pores where the capillary law holds and where capillary forces are much greater than gravitational forces. The effect of gravity can be accounted for through a correction factor that should be developed in order to enlarge the applicability range of the method to coarser materials.

Van Brakel et al. ${ }^{15}$ have argued that measurements of surface areas by mercury porosimetry will never be reliable because of the structure hysteresis observed in the curves $V(P)$ depending on whether the mercury is injected or extracted. Indeed, the assumption made on the reversibility of the work during an intrusion or an extraction process may break down because of the interconnectivity of the pores and because of the existence of ink bottles and dead ends in the material. In addition, results can be affected by the sample deformations due to the high pressures required to inject mercury in powders. However, the assumption of reversibility can be checked and if it breaks down, an average value and limits can be worked out and compared to BET measurements for finely dispersed media. We did not investigate the structure hysteresis at the moment because this would have required a more complicated experimental setup. In our experiments, the same assumptions are made as by Rootare and Prenslow but the effect of sample deformation is thought to be of less importance because the pressures involved are less when using water to fill bigger pores. Considering the reasonably good agreement between the measured and the calculated specific areas, the method can be considered as reliable and more adapted to the coarse materials encountered in acoustics than the BET used for very finely dispersed materials with higher specific areas.

\section{SPECIFIC AREA AND ACOUSTICS OF POROUS MEDIA}

The specific area is widely used in chemistry and in other fields of physics. It is an important parameter for the physical study of wave propagation in porous media. 
For some new acoustic materials such as those fabricated from loose solid particles consolidated with a binder or such as porous foams impregnated with a chemicals, ${ }^{16}$ the specific area can be used to evaluate the average thickness of the layer $h$, provided it is thin with respect to the pore size. Assuming a constant film spreading over the solid surface, a simple calculation yields the following expression that can be used in a first approximation:

$$
h S_{S}=\frac{\gamma_{l}}{\rho_{l}},
$$

where $\gamma_{l}$ and $\rho_{l}$ are respectively the mass content and the density of the added matter. In the case of Coustone, the density of binder being $1130 \mathrm{~kg} / \mathrm{m}^{3}$ and the binder content being respectively $0.03,0.015$ and 0.06 for the grades $N, \frac{1}{2}$, and 2, the application of Eq. (10) gives the values 29,11 and $41 \mu \mathrm{m}$, respectively, for the average thickness of binder. In fact, the layer thickness is not constant for high concentrations of binder and only a fraction spreads over the solid surface while the rest accumulates between the grains. ${ }^{17}$ For the same reason, this simple evaluation would not hold for materials with a strong surface roughness or with a fractal porosity. Nevertheless, Eq. (10) can be considered as a good starting point for a more refined physical analysis.

Important contributions to the physical study of elastic wave propagation in porous media have been brought out by Johnson et al. ${ }^{1}$ and by Champoux and Allard ${ }^{2}$ who have introduced the concepts of viscous characteristic length $\Lambda$ and of thermal characteristic length $\Lambda^{\prime}$. These two parameters are necessary for the acoustic description in the full frequency range without making assumptions on the pore shape.

The viscous characteristic length $\Lambda$ is given by the volume-to-surface ratio weighted by the fluid velocity field in the pore: ${ }^{1}$

$$
\Lambda=2 \frac{\int|v(r)|^{2} d V}{\int\left|v\left(r_{w}\right)\right|^{2} d S} .
$$

At this time, the experimental determination of $\Lambda$ is possible only under particular conditions or for certain materials. The intrinsic definition (11) does not allow any direct measurement for every materials, but an estimation via the thermal length is possible knowing that $\Lambda$ is generally between 1.5 and 3 times less than $\Lambda^{\prime}$. A direct evaluation of $\Lambda$ would require the additional knowledge of the velocity field in the pores. by $^{2}$

For a material of porosity $\phi$, the thermal length is given

$$
\Lambda^{\prime}=2 \frac{\int d V}{\int d S}=2 \frac{\phi}{S_{S} \rho_{s}} .
$$

Lemarinier et al. ${ }^{18}$ have shown the connection between the specific area, the thermal length and the dynamic compressibility of air in high porosity plastic foams. They have evaluated $\Lambda^{\prime}$ from measurements of specific area by the BET method. The BET method is an original method based on the adsorption of the molecules of a gas by the particles of a powder. For a given quantity of powder (generally a few grams), the precision depends on the gas used and on the grain size. The quantity of gas adsorbed being proportional to the surface, the problem consists in determining the number of moles contained in a single layer and the total amount adsorbed on the solid surface. The model generally used to evaluate this amount is the one released by Brunauer, Emmet and Teller. ${ }^{13}$ This method is widely used for the characterization of powders in chemistry and pharmaceutical industry where the order of magnitude of the measured specific areas is greater than a few dozens of $\mathrm{m}^{2} / \mathrm{g}$. The method proposed in this article is an alternative and complementary method to the BET technique that should apply to many acoustic materials whose specific areas, of a few $\mathrm{m}^{2} / \mathrm{kg}$, are much lower than those of powders. The overall thermal lengths calculated for our samples from the experimental data are displayed in Table II.

On the basis of the theory of Johnson et al., ${ }^{1}$ Lafarge et al ${ }^{4}$ have extended the model of Champoux and Allard ${ }^{2}$ and proposed a more refined analysis of thermal exchanges in air-filled porous structures introducing the concept of a dynamic thermal permeability $k^{\prime}(\omega)$ as a function of the angular frequency $\omega$. The low frequency limit of $k^{\prime}(\omega)$ is a geometrical constant called the thermal permeability $k_{0}^{\prime}$. This new parameter has been identified as the inverse of the trapping constant $\Gamma$ which is a parameter defined in problems of diffusion-controlled reactions in disordered media. ${ }^{19}$ The trapping constant has been measured recently by an acoustical method. ${ }^{20}$ Lafarge et al. have shown that the knowledge of the trapping constant (or the thermal permeability $k_{0}^{\prime}$ ) and of the specific area (or the thermal length $\Lambda^{\prime}$ ) is enough to predict, in the whole frequency range, the dynamic compressibility of air and therefore the acoustical properties of air-filled porous media.

\section{CONCLUSION}

A method for measuring the specific area of acoustic materials has been proposed and tested for several grades of glass beads and materials used in civil engineering. This method is modelless and is based on the integration of the work required to extract water from a porous sample by capillary action. A good accuracy $(6.5 \%-9.9 \%)$ has been obtained for the smallest particle size $(0.68-1.1 \mathrm{~mm})$ while the method fails for higher grades (17.5\% for $1.64 \mathrm{~mm}$ beads) because of the effect of gravity acting on water. Nevertheless, the precision can be improved for coarse materials and the method can be considered as reliable and well adapted to acoustic materials.

The surface area is an important parameter for the study of porous media from the physical standpoint simply because the fluid/solid interface represents the frontier where the physicochemical reactions take place and where the energy exchanges occur. It is needed for the microscopic characterization of modern acoustic materials and for the description of the acoustic properties of air-filled materials in the whole frequency range. 


\section{ACKNOWLEDGMENTS}

The authors thoroughly thank D. C. Hothersall, J. F. Allard, A. Cummings and A. A. Javadi for their comments on this article and for their enlightening remarks. They are also grateful to E. Chadwick of Sound Absorption LTD., Bacup, Lancashire, UK, for providing acoustic materials and for stimulating discussions. This work has been made under the British Engineering and Physical Sciences Research Council (EPSRC) Grant No. C36.

'D. L. Johnson, J. Koplik, and R. Dashen, J. Fluid Mech. 176, 379 (1987). ${ }^{2}$ Y. Champoux and J. F. Allard, J. Appl. Phys. 70, 1975 (1991).

${ }^{3}$ J. F. Allard, Sound Propagation in Porous Media: Modeling Sound Absorbing Materials (Elsevier, London, 1993).

${ }^{4}$ D. Lafarge, P. Lemarinier, J. F. Allard, and V. Tarnow, J. Acoust. Soc. Am. 102, 1995 (1997).

${ }^{5}$ T. Yamamoto and A. Turgut, J. Acoust. Soc. Am. 83, 1744 (1988).

${ }^{6} \mathrm{~K}$, Attenborough, Acta. Acust. 1, 213 (1993).

${ }^{7}$ J. F. Allard, B. Castagnède, M. Henry, and W. Lauriks, Rev. Sci. Instrum. 65. 754 (1994).

${ }^{8}$ N. Brown, M. Melon, B. Castagnède, V. Montembault, W, Lauriks, and P.
Leclaire, C. R. Acad. Sci., Ser. IIb: Mec., Phys., Chim., Astron. 322, 121 (1996).

${ }^{9}$ P. Leclaire, L. Kelders, W. Lauriks, M. Melon, N. Brown, and B. Castagnède, J. Appl. Phys. 80, 2009 (1996).

${ }^{10} \mathrm{P}$. Leclaire, L. Kelders, W. Lauriks, J. F. Allard, and C. Glorieux, Appl. Phys. Lett. 69, 2641 (1996).

${ }^{11}$ S. Lowell and J. E. Shields, Powder Surface Area and Porosity (Chapman and Hall, New York, 1984).

${ }^{12}$ H. M. Rootare and C. F. Prenzlow, J. Phys. Chem. 71, 2733 (1967).

${ }^{13}$ S. Brunauer, P. H. Emmet, and E. Teller, J. Am. Chem. Soc. 60, 309 (1938).

${ }^{14}$ J. E. Evans, Measuring the pore size distribution of a model granular material using a water suction method. Working paper/Internal report, Department of Engineering Mechanics, The Open university, Milton Keynes, UK (unpublished).

${ }^{15}$ J. Van Brakel, S. Modrỳ, and M. Svatà, Powder Technol. 29, 1 (1981).

${ }^{16} \mathrm{P}$. Lemarinier, Ph.D. thesis, Université du Maine, Le Mans, France, 1997.

${ }^{17}$ E. Chadwick (private communication).

${ }^{18}$ P. Lemarinier, M. Henry, J. F. Allard, J. L. Bonardet, and A. Gédéon, J. Acoust. Soc. Am. 97, 3478 (1995).

${ }^{19}$ G, H. Weiss, J. Stat. Phys. 42, 3 (1986).

${ }^{20}$ A. Debray, J. F. Allard, W. Lauriks, and L. Kelders, Rev. Sci. Instrum. 68, 4462 (1997). 